\title{
A modified basket catheter technique with semi-rigid ureterorenoscopy in the prevention of migration of proximal ureteral stones
}

\author{
Abdullah Erdoğan॰, Ercüment Keskin॰ \\ Department of Urology, Erzincan Binali Yıldırım University School of Medicine, Erzincan, Turkey
}

\begin{abstract}
Objectives: Although proximal ureteral stones are common, some difficulties are encountered in semi-rigid ureterorenoscopy (URS) treatment, especially as a result of stone migration to the kidney. In this paper, we present a different use of a basket catheter for the treatment of proximal ureteral stones.

Methods: Between September 2016 and January 2019, 101 patients over 18 years of age detected to have a maximum 15-mm proximal ureteral stone were retrospectively evaluated, and 93 patients fulfilling the criteria were included in the study. Semi-rigid URS and a modified basket catheter were used together in 44 patients while no auxiliary equipment was utilized for the remaining 49 patients. In the study group, a 3F zero-tip basket catheter was disintegrated and positioned in a way to capture and retrieve the stone from the semi-rigid ureterorenoscope.

Results: No difference was found between the two groups in terms of age, body mass index, gender, and stone characteristics. The duration of operation was shorter in the basket catheter group $(p<0.001)$. The rates of stone migration, requirement to switch to flexible ureterorenoscopy (FURS), and double J-stent (JJ-stent) placement were significantly higher in the control group $(p<0.005)$. There were no significant differences between the two groups concerning operation success and complications $(p=0.068$ and $p=0.772$, respectively).

Conclusions: The modified basket catheter technique with semi-rigid URS was successful in preventing the migration of proximal ureteral stones. This method can be considered as an alternative in cases where FURS is not available.
\end{abstract}

Keywords: Basket catheter technique, proximal ureteral stones, semi-rigid ureterorenoscopy

$\mathrm{U}$ reteral stones are one of the most common urological problems, with treatment options varying according to the location, size and composition of the stone, patient preference, experience of the surgeon, and availability of auxiliary equipment [1]. During treatment with a semi-rigid ureterorenoscopy (URS), the proximal location of the stone both reduces treatment success and increases complication rates [2].
Therefore, the use of flexible URS (FURS) is recommended for the surgical treatment of proximal ureteral and renal pelvic stones [1]. The retrograde migration of stones to the kidney is reported to vary between 3 and $15 \%$ for distal ureteral stones $[3,4]$, but this rate can reach $60 \%$ for stones located in the proximal ureter [5-7]. The treatment of stones that have migrated to the kidney require additional procedures, 
repetition of surgery, and JJ stent applications, which increase the morbidity rates and treatment cost.

In order to increase the success of the procedure and prevent stone migration, many mechanic devices (wire-balloon) and gels have been developed and provided successful results when placed in the proximal part of the stone. Stone baskets, such as LithoCatch ${ }^{\circledR}$, Parachute $^{\circledR}$ and Escape ${ }^{\circledR}$, as well as vacuum device Lithovac $^{\circledR}$, balloon basket Parachute ${ }^{\circledR}$, and Stone Cone $^{\circledR}$, PercSys Accordion ${ }^{\circledR}$ and NTrap ${ }^{\circledR}$ that form a barrier in the proximal of the stone are among mechanical tools designed to prevent stone migration [8-16]. In addition, BackStop ${ }^{\circledR}$ gel is a temporary congestion-forming substance in the heat-sensitive proximal of the stone to prevent migration [17].

With these developments, the relatively high cost of auxiliary equipment has led to the search for a cheaper and more effective method due to the limited health budget. In the current study, we aimed to present a different use of a basket catheter to prevent migration of proximal ureteral stones.

\section{METHODS}

After obtaining the approval of the university's Ethics Committee, 101 patients older than 18 years of age detected to have a proximal ureteral stone with a maximum diameter of $15 \mathrm{~mm}$ between September 2016 and January 2019 were retrospectively evaluated. Patients with congenital anomalies, accompanying renal stones or multiple ureteral stones were excluded from the study. Stone could not be reached in three patients due to the kinking of the proximal ureter. JJ stents were implanted in two of these patients and percutaneous nephrolithotomy (PNL) was performed in the last patient. Five patients were found to have pyonephrosis, of whom two were treated with a percutaneous nephrostomy catheter and three received a $\mathrm{JJ}$ stent. The patients who underwent PNL, nephrostomy and JJ stent were also excluded from the study.

The age, gender, body mass index (BMI) and comorbid disease history of the patients were recorded. In addition, hemogram, blood urea nitrogen, creatinine and urinalysis tests were conducted preoperatively. Stone localization was determined by computerized tomography (CT). The largest diameter of the stone was recorded and the stone volume was calculated as $\mathrm{mm} 2$ by multiplying the length and width measured on CT. URS was scheduled for patients that did not pass the stone through conservative treatment, those resistant to extracorporeal shock wave lithotripsy (ESWL)with non effective ESWL, and those for whom surgery was preferred due to severe pain and hydronephrosis.

Semi-rigid URS was performed in 93 patients (41 female, 52 male), who met the study criteria. A modified basket catheter was used in combination with URS in 44 patients, while the remaining 49 patients underwent URS without auxiliary equipment. A ureteral stricture that prevented the passage of URS in the distal of the stone was detected in six patients in the control group and four patients in the study group. In these patients, balloon dilation was performed under fluoroscopic control and the operation was continued.

In the control group, no auxiliary equipment was used to prevent stone migration. In the study group, a 3F zero-tip basket catheter (Baycare, Bayrak Medikal, Turkey,) was reconfigured and positioned in a way to capture and retrieve the stone from the ureterorenoscope (Karl Storz 9-11F, Tuttlingen, Germany) (Figs. 1 and 2). Then, ureterorenoscope was taken out and a laser lithotripter was introduced through the ureterorenoscope adjacent to the basket catheter to fragment the stone (Fig. 3). When this procedure was completed, the basket was removed from the ureter and used in the same configuration for stone retrieval from the URS. During stone extraction, if there was anything that blocked passage in any section of the ureter, the ureterorenoscope was taken out and the stone fragmentation process was repeated using the lithotripter running adjacent to the basket catheter (Fig. 4). The detached basket catheter technique was implemented by two surgeons with similar experience. A laser fiber of $365-\mu \mathrm{m}$ in thickness was used in all patients. Stone fragmentation was performed at a laser frequency of $5 \mathrm{~Hz}$ and power of 1.5 Joules. The two groups were compared in terms of stone migration, peroperative requirement of switching to FURS, intraoperative and postoperative complications, JJ stent placement, operation time and success, postoperative ESWL, and second surgery requirement. The operation success was assessed at the postoperative third week using Kidney-Ureter-Bladder (KUB) X-ray in 


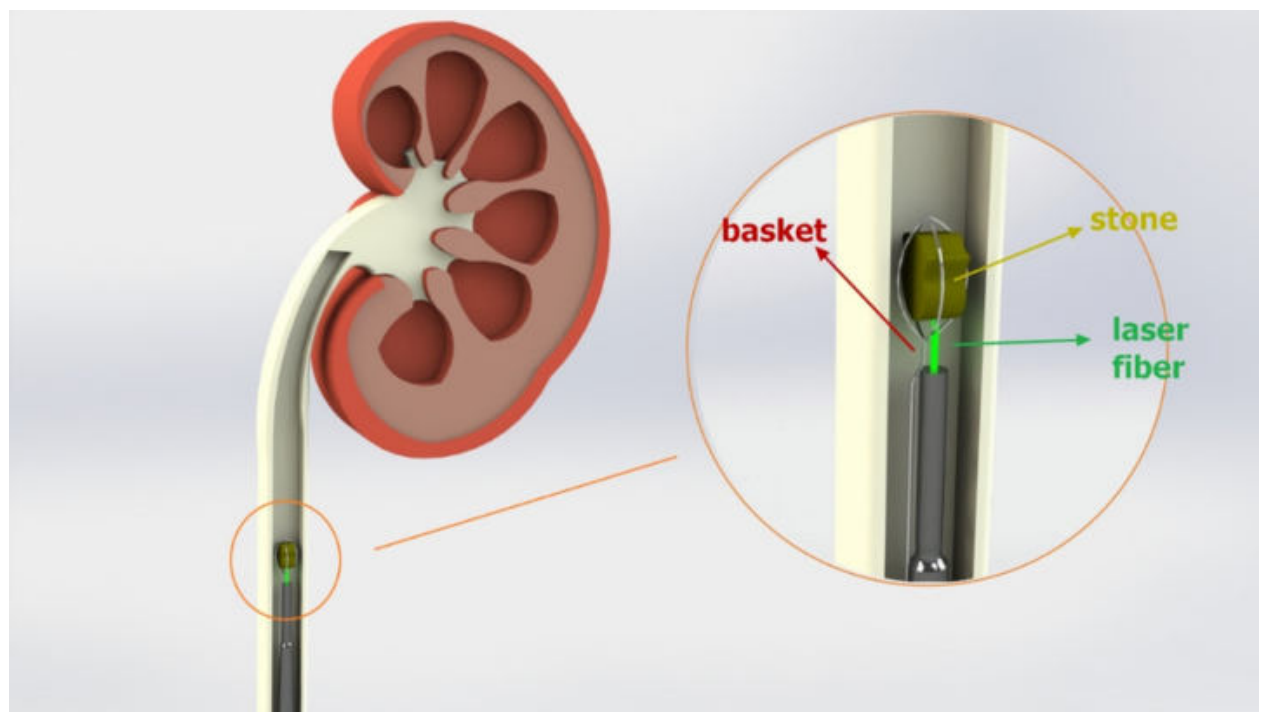

Fig 1. Schematic view of the use of the modified basket catheter.

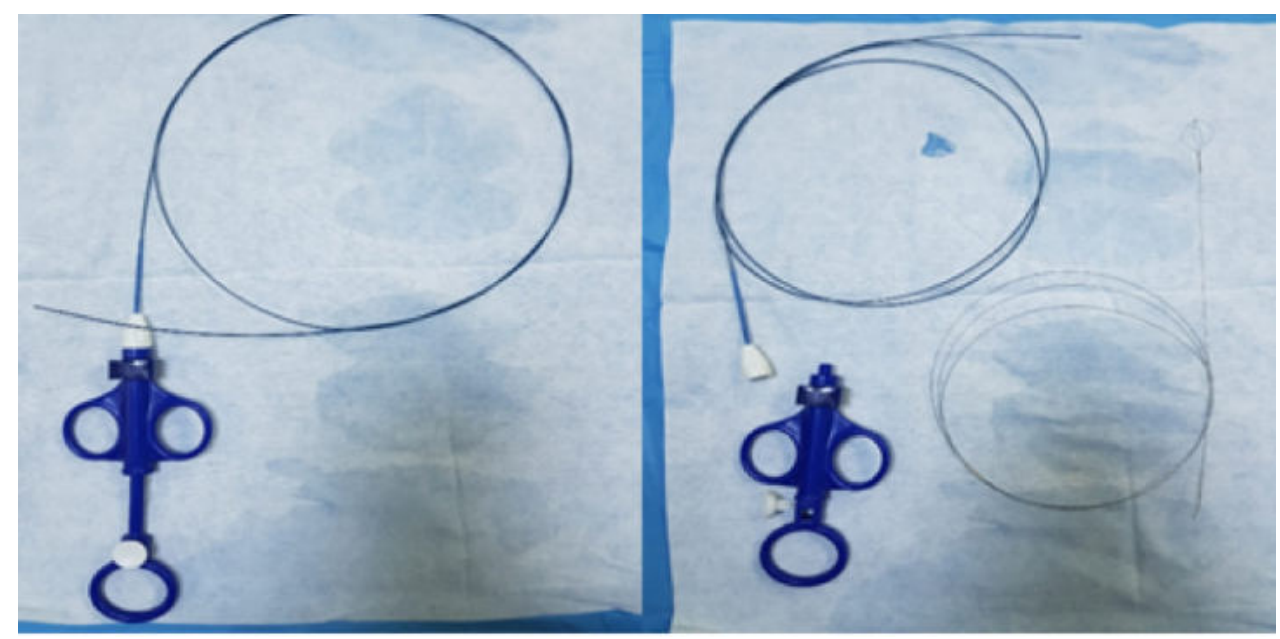

Fig 2. Normal and modified configuration of the basket catheter.

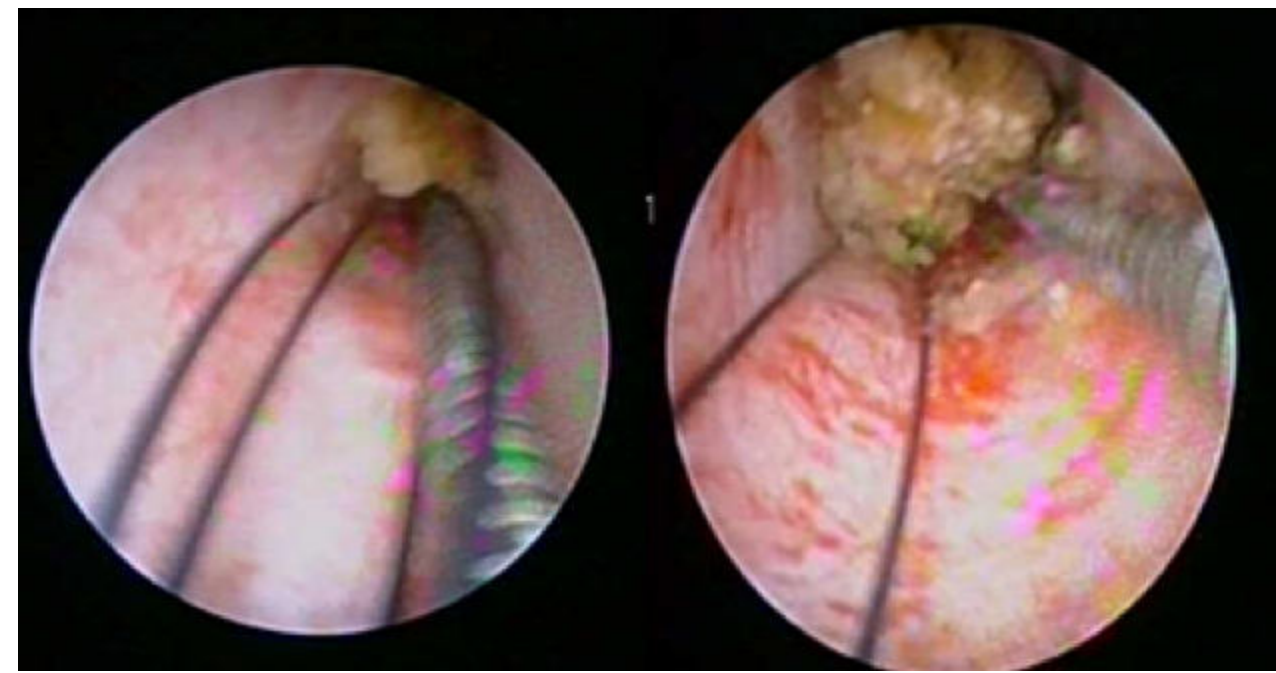

Fig 3. Engagement of the stone by the modified basket catheter. 


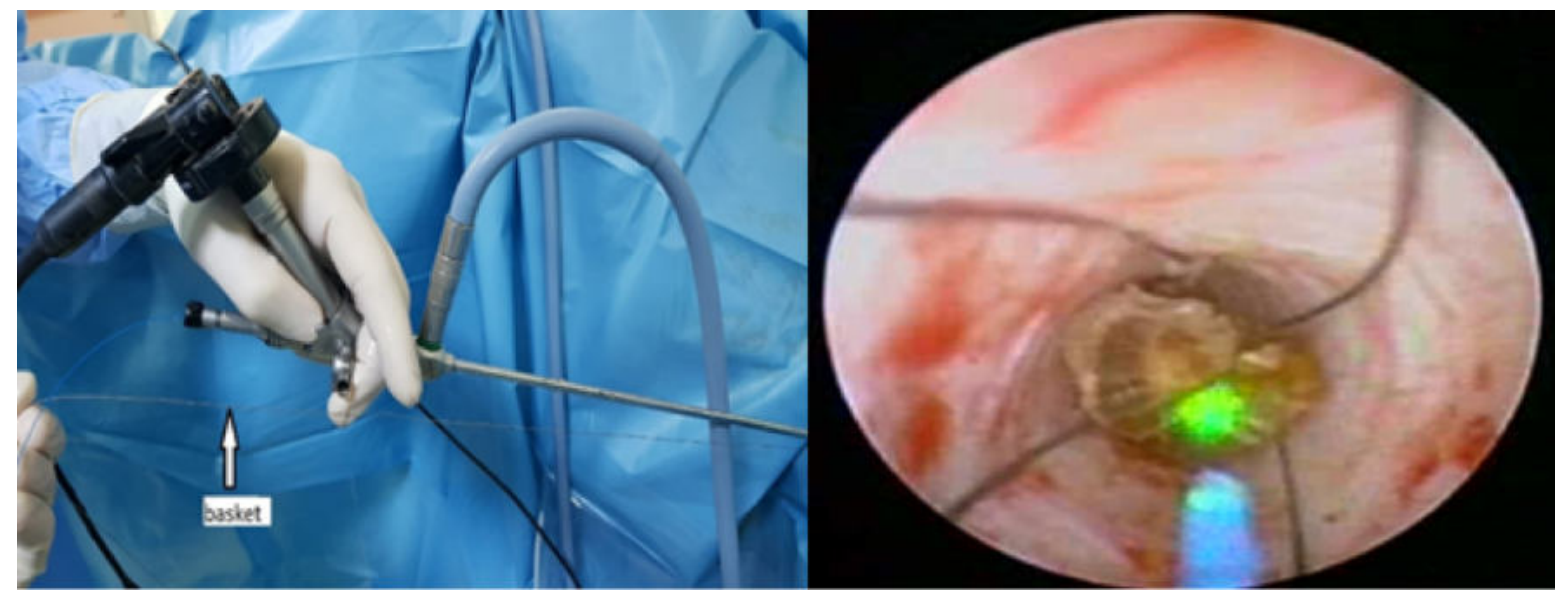

Fig 1. Schematic view of the use of the modified basket catheter.

opaque stones and ultrasonography and non-contrast $\mathrm{CT}$ in non-opaque stones.

\section{Statistical Analysis}

The data were analyzed using SPSS version 25.0 (SPSS ${ }^{\circledR}$, IL, USA). Normally distributed data were presented as mean \pm standard deviation (SD). Student's t-test was employed for continuous variables, and chi-square and Fisher's exact tests for categorical variables. $p<0.05$ was considered statistically significant.

\section{RESULTS}

The mean age of the patients was $48.2 \pm 15.9$ years and the mean stone length was $10.7 \pm 2.1 \mathrm{~mm}$. No difference was found between the two groups in terms of age, BMI, gender, and stone characteristics (Table 1). The mean operative time was $49.5 \pm 10.1$, and the duration of operation was shorter in the basket catheter group $(p<0.001)$. The rates of stone migration, requirement of FURS and JJ-stent placement were significantly higher in the control group $(p<$ 0.005). No significant difference was found between the two groups concerning operation success and complications ( $p=0.068$ and $p=0.772$, respectively) (Table 2).

Stone migration to the kidney was observed in five patients in the study group during surgery. In three of these patients, the stone was not visualized in the proximal ureter at first insertion (considered to be due to the irrigation fluid causing stone migration to the kidney), whereas for the two remaining cases, the stone migrated during the procedure. In two of the three patients whose stone was not visualized at first insertion and one of the two patients with peroperative stone migration, the stone was captured using the basket catheter in the renal pelvis and pulled into the proximal ureter; then, stone fragmentation was applied. It was necessary to switch to FURS in two patients in the study group. In the control group, the

Table 1. Comparison of the demographic and stone characteristics of the patients

\begin{tabular}{lccc}
\hline & Basket catheter group & Control group & $\boldsymbol{p}$ value \\
\hline Age $($ years $)$ & $45.16 \pm 13.9$ & $51.02 \pm 17.2$ & 0.077 \\
BMI $\left(\mathrm{kg} / \mathrm{m}^{2}\right)$ & $25.7 \pm 3.5$ & $24.8 \pm 3.2$ & 0.233 \\
Gender $(\mathrm{F} / \mathrm{M})$ & $21 / 23$ & $20 / 29$ & 0.503 \\
Stone side (right/left) & $19 / 25$ & $26 / 23$ & 0.341 \\
Stone width $(\mathrm{mm})$ & $11.02 \pm 2.7$ & $10.43 \pm 1.32$ & 0.191 \\
Stone volume $\left(\mathrm{mm}^{2}\right)$ & $100.9 \pm 49.8$ & $91.18 \pm 22.04$ & 0.238 \\
\hline
\end{tabular}

$\mathrm{BMI}=$ body mass index 
stone was not visualized in two patients at first insertion, and stone migration occurred in 25 further patients during surgery, making the total 27 . It was seen that in 13 of the 27 patients, the stone was fragmented; thus, a JJ stent was implanted and the procedure was terminated. For the remaining 14 patients, FURS was utilized. Mild mucosal injury and hematuria occurred in two patients in the study group. In the control group, three patients had hematuria and four patients had mild mucosal injury that did not require termination of the operation. In the postoperative period, urinary tract infection developed in four patients in the study group and three patients in the control group. None of the patients had a ureteral stricture. The postoperative complications were evaluated according to the Modified Clavien (MC) classification (Table 2).

\section{DISCUSSION}

When the ureteral stones are classified according to their localization, those located in the proximal ureter have higher migration and complication rates and lower operative success compared to those in the mid-distal ureter $[2,18]$. The type of energy used in the fragmentation of the stone also affects migration and the success of the operation [19-21]. Stone-Cone is one of the tools devised to prevent stone migration and it is recommended for use in the treatment of ureteral stones due to significantly reducing the possibility of stone migration $[8,20]$. However, although this device increases the operation success, it cannot be effectively used in the retrieval of fragmented stones. In addition, Stone-Cone is more effective in dilated stones of $7-10 \mathrm{~mm}$ in diameter. If the dilatation in the proximal of the stone is more than $10 \mathrm{~mm}$, the effect of the device is reduced. In the current study, since we used a modified configuration of a basket catheter to engage the stone, proximal ureter dilatation was not important. Considering that the inner diameter of the basket is $15 \mathrm{~mm}$, it can be used to prevent the migration of stones of this size. A further study to compare Stone-Cone and the modified basket catheter in the prevention of stone migration can provide clearer data.

Table 2. Comparison of the study and control groups in terms of the operation outcomes and complications

\begin{tabular}{|c|c|c|c|}
\hline & Basket catheter group & Control group & $p$ value \\
\hline \multicolumn{4}{|l|}{ Stone migration, $\mathrm{n}(\%)$} \\
\hline First insertion & $3(6.9 \%)$ & $2(4.08 \%)$ & \\
\hline During procedure & $2(4.5 \%)$ & $25(51.02 \%)$ & \\
\hline Total & $5(11.4 \%)$ & $27(55.1 \%)$ & $<0.001$ \\
\hline Use of FURS, n (\%) & $2(5.5 \%)$ & $14(28.6 \%)$ & 0.002 \\
\hline Complete stone-free rate, $\mathrm{n}(\%)$ & $36(81.8 \%)$ & $30(61.2 \%)$ & \\
\hline \multicolumn{4}{|l|}{ Residual fragments, n (\%) } \\
\hline$\leq 3 \mathrm{~mm}$ & $6(13.6 \%)$ & $11(22.4 \%)$ & 0.068 \\
\hline$>3 \mathrm{~mm}$ & $2(4.5 \%)$ & $8(16.3 \%)$ & \\
\hline JJ stent requirement (n) & $28(63.6 \%)$ & $43(87.8 \%)$ & 0.006 \\
\hline Operation time (min) & $42.27 \pm 7.54$ & $56.1 \pm 7.24$ & $<0.001$ \\
\hline \multicolumn{4}{|l|}{ Complications, n (\%) } \\
\hline $\mathrm{MC1}$ & $6(13.6 \%)$ & $7(14.3 \%)$ & \\
\hline $\mathrm{MC} 2$ & $5(11.4 \%)$ & $8(16.3 \%)$ & 0.772 \\
\hline Postoperative ESWL, n (\%) & $1(2.3 \%)$ & $5(10.2)$ & 0.207 \\
\hline Second surgery, $\mathrm{n}(\%)$ & $1(2.3 \%)$ & $3(6.1 \%)$ & 0.619 \\
\hline
\end{tabular}

FURS $=$ flexible ureterorenoscopy, $\mathrm{JJ}=$ Double $\mathrm{j}, \mathrm{MC}=$ modified Clavien classification, ESWL $=$ extracorporeal shock wave lithotripsy 
The basket catheter is primarily designed for the removal of stone fragments from the ureter. In case of any entrapment occurring during the procedure, basket catheter can be disintegrated. This design allows the free release of the ureterorenoscope from the ureter. In the presented technique, the modified basket catheter was used to both prevent stone migration and retrieve residual stones after fragmentation.

In the study of Kesler et al. [9] concerning the Escape ${ }^{\circledR}$ basket (Boston Scientific Corp., Natick, MA, USA) and that of Kroczak et al. [10] investigating a basket catheter, the basket and laser were both inside the ureterorenoscope. In contrast, in the current study, the ureterorenoscope and laser were used independently from the basket catheter. The basket catheter being located adjacent to the ureterorenoscope, not inside, allows the use of a thicker laser fiber in the working channel. We also consider that this facilitates the flow of the irrigation fluid and allows the ureterorenoscope to be more easily manipulated. In his study with a small group of patients, Kesler et al. [9] determined the complete stone-free rate to be $100 \%$, but he did not refer to stone localization or stone migration. In another study investigating the dual use of a basket catheter, Kroczak et al. [10] reported stone migration in 10 patients (14.7\%), which is similar to the rate determined in the current study (five patients; 11.4\%). However, the requirement of switching to FURS was lower in our study (two patients; $5.5 \%$ ) compared to the study by Kroczak et al. [10] (19 patients; 24.1\%). Lastly, our higher rate of $\mathrm{JJ}$ stent requirement in the control group may be due to the requirement of FURS in more patients in this group.

Since most devices that prevent stone migration cannot be used for stone extraction, the cost of surgery increases. Therefore the EAU guidelines recommends the need and use of a FURS in such cases independently of the retropulsion device.In the presented technique, the basket catheter, which is cheaper than other migration-preventing equipment, not only reduced the possibility of stone migration but also helped to retrieve stone fragments from the ureter, reducing the total cost of surgery.

One of the drawbacks of using a basket catheter to prevent stone migration is that the laser damages the wires of the basket. In the current study, we had to use a second basket in five patients because the laser cut the single wire of the basket. However, this did not harm any of the patients and the basket was successfully removed as a whole. Our complication rates in both groups were similar to those reported in previous studies [23, 24], and we did not observe any major complication.

We consider that the lack of a statistically significant difference between the two groups in terms of operative success was due to the continuation of surgery by switching to the use of FURS in cases of stone migration in the control group. This may also be one of the reasons for the longer duration of operation in the control group. Although we have access to FURS, it is an expensive device with a limited lifetime; therefore, we suggest that using semi-rigid URS as a safe and effective method for the treatment proximal ureter stones and switching to the use of FURS in cases where necessary will reduce the cost of surgery without compromising patient safety.

\section{Limitations}

The limitations of our study include the retrospective nature and non-randomized design. Furthermore, not all the patients underwent $\mathrm{CT}$ in the postoperative follow-up, with ultrasonography and KUB X-ray being used in some cases. This may be regarded as another limitation considering that CT follow-up after stone surgery has been shown to be superior in showing residual fragments [25]. Randomized controlled prospective studies with other migration-preventing devices are needed to better demonstrate the efficacy of the presented method.

\section{CONCLUSION}

In conclusion, the modified basket catheter technique is effective in preventing the migration of proximal ureter stones when applied with semi-rigid URS. This method can be used as an alternative when FURS is not available or resources are limited and FURS is reserved for more complicated cases requiring longer-term treatment.

\section{Conflict of interest}

The authors disclosed no conflict of interest dur- 
ing the preparation or publication of this manuscript.

\section{Financing}

The authors disclosed that they did not receive any grant during conduction or writing of this study.

\section{REFERENCES}

1. Türk C, Neisius A, Petrik A, Seitz C. EAU Guidelines on Urolithiasis. 2018.

2. Yencilek F, Sarica K, Erturhan S, Yagci F, Erbagci A. Treatment of ureteral calculi with semirigid ureteroscopy: where should we stop? Urol Int 2010;84:260-4.

3. Hendrikx AJ, Strijbos WE, de Knijff DW, Kums JJ, Doesburg WH, Lemmens WA. Treatment for extended mid and distal ureteral stones: SWLor ureteroscopy? Results of a multicentre study. J Endourol 1999;13:727-33.

4. Pardalidis NP, Kosmaoglou EV, Kapotis CG. Endoscopy vs. extracorporeal shockwave lithotripsy in treatment of distal ureteral stones: 10 years experience. J Endourol 1999;13:161-4. 5. Rane A, Bradoo A, Rao P, Shivde S, Elhilali M, Anidjar M, et al. The use of a novel reverse thermosensitive polymer to prevent ureteral stone retropulsion during intracorporeal lithotripsy: a randomized, controlled trial. J Urol 2010;183:1417-21.

6. Segura JW, Preminger GM, Assimos DG, Dretler SP, Kahn RI, Lingeman JE, et al: Ureteral Stones Clinical Guidelines Panel summary report on the management of ureteral calculi. The American Urological Association. J Urol 1997;158:1915-21.

7. Dretler SP. The stone cone: a new generation of basketry. J Urol 2001;165:1593-6.

8. Pardalidis NP, Papatsoris AG, Kosmaoglou EV. Prevention of retrograde calculus migration with the Stone Cone. Urol Res 2005;33:61-4.

9. Kesler SS, Pierre SA, Brison DI, Preminger GM, Munver R. Use of the escape nitinol stone retrieval basket facilitates fragmentation and extraction of ureteral and renal calculi: a pilot study. J Endourol 2008;22:1213-7.

10. Kroczak T, Ghiculete D, Sowerby R, Ordon M, Lee JY, Pace KT, et al. Dual usage of a stone basket: stone capture and retropulsion prevention. Can Urol Assoc J 2018;12:280-3.

11. Geavlete P, Georgescu D, Niţă G, Mirciulescu V, Cauni V. Complications of 2735 retrograde semirigid ureteroscopy procedures: a single-center experience J Endourol 2006;20:179-85.
12. Eisner BH, Dretler SP. Use of the Stone Cone for prevention of calculus retropulsion during holmium:YAG laser lithotripsy: case series and review of the literature. Urol Int 2009;82:356-60. 13. Park J, Hong B, Park T, Park HK. Effectiveness of noncontrast computed tomography in evaluation of residual stones after percutaneous nephrolithotomy. J Endourol 2007;21:684-7.

14. Chow GK, Patterson DE, Blute ML, Segura JW. Ureteroscopy: effect of technology and technique on clinical practice. J Urol 2003;170:99-102.

15. Knispel HH, Klan R, Heicappell R, Miller K. Pneumatic lithotripsy applied through deflected working channel of miniureteroscope: results in 143 patients. J Endourol Soc 1998;12:513-5.

16. Tunc L, Kupeli B, Senocak C, Alkibay T, Sozen S, Karaoglan $\mathrm{U}$, et al. Pneumatic lithotripsy for large ureteral stones: is it the first line treatment? Int Urol Nephrol 2007;39:759-64.

17. el-Gabry EA, Bagley DH. Retrieval capabilities of different stone basket designs in vitro. J Endourol 1999;13:305-7.

18. Delvecchio FC, Kuo RL, Preminger GM. Clinical efficacy of combined lithoclast and lithovac stone removal during ureteroscopy. J Urol 2000;164:40-2.

19. Dretler SP. Ureteroscopy for proximal ureteral calculi: prevention of stone migration. J Endourol 2000;14:565-7.

20. Dellabella M, Milanese G, d'Anzeo G, Muzzonigro G. Rapid, economical treatment of large impacted calculi in the proximal ureter with ballistic ureteral lithotripsy and occlusive, percutaneous balloon catheter: the high pressure irrigation technique. $\mathrm{J}$ Urol 2007;178(3 Pt 1):929-33.

21. Holley PG, Sharma SK, Perry KT, Turk TMT. Assessment of novel ureteral occlusion device and comparison with stone cone in prevention of stone fragment migration during lithotripsy. $\mathrm{J}$ Endourol 2005;19:200-13.

22. Percutaneous System, Inc. PercSys Accordian stone management device document [online], http://www.percsys.com/SMD.html.

23. Olbert PJ, Keil C, Weber J, Schrader AJ, Hegele A, Hofmann R. Efficacy and safety of the Accordion stone-trapping device: in vitro results from an artificial ureterolithotripsy model. Urol Res 2010;38:41-6.

24. Chen S, Zhou L, Wei T, Luo D, Jin T, Li H, et al. Comparison of Holmium: YAG laser and pneumatic lithotripsy in the treatment of ureteral stones: an update meta-analysis. Urol Int 2017;98:125-33.

25. Sun Y, Wang L, Liao G, Xu C, Gao X, Yang Q, et al: Pneumatic lithotripsy versus laser lithotripsy in the endoscopic treatment of ureteral calculi. J Endourol 2001;15:587-90. 